\title{
AVALIAÇÃO DO FÓSFORO EM FERTILIZANTES ATRAVÉS DA SOLUÇÃO DE ÁCIDO CÍTRICO A 2\%: TÉCNICAS DE EXTRAÇÃO*
}

\author{
J. C. ALCARDE ** \\ V. T. PAULINO ***
}

RESUMO

Neste trabalho estudou-se o comportamento da solução de ácido cítrico a $2 \%$ quando aplicada na avaliação do fósforo em fertilizantes fosfatados simples soluveis em água e em misturas contendo fosfatos insolúveis em água, efetuando-se a extração sob duas condições: diretamente na amostra e, portanto, em presença dos componentes solúveis em água e após a extração dos componentes solúveis em água, à semelhança da técnica de extração classicamente estabelecida para a solução de citrato de amônio.

Os resultados, comparados entre si e com os obtidos pelo critério da solubilidade em água e em solução de citrato de amônio, permitiram concluir que a extração cítrica efetuada diretamente na amostra e na relação 1:100 é afetada pela presença dos componentes solúveis em água; a fração insolúvel em água dos fertilizantes fosfatados simples solúveis em água apresentou maior solubilidade na solução de citrato de amônio e menor na solução de ácido cítrico com extração direta; a fração insolúvel $\mathrm{cm}$ água das misturas de fertilizantes contendo rocha fosfatada apresentaram maior solubilidade na solução de ácido cítrico com extração efetuada após a eliminação dos componentes solúveis em água. A mistura que continha farinha de ossos degelatinados apresentou solubilidade semelhante nas três técnicas de extração estudadas.

\section{INTRODUÇÃO}

Cada nutriente vegetal pode ser usado nos fertilizantes sob várias formas, diferentes na natureza, nas propriedades e ou no comportamento agronômico. Isso tem contribuído para uma série de aspectos benéficos do ponto de vista agrícola, principalmente porque possibilita atender as exigências nutricionais dos vegetais com mais especificidade

* Entregue para publicação em 30.12.76.

* Departamento de Química da Escola Superior de Agricultura "Luiz de Queiroz".

** Bolsista do CNPq. 
na prática das adubações. Atualmente, as pesquisas estão dirigidas no sentido de dotar os nutrientes vegetais de variedades de formas possíveis de serem usadas como fertilizantes, notadamente aquelas de lenta liberação" (slow release) do elemento nutritivo.

Para a maioria dos nutrientes essas variações, pelo menos até agora, não tem apresentado maiores problemas no estabelecimento de padrões de qualidade para os fertilizantes, e nem nas suas respectivas avaliações em condições de laboratório, visando a comercialização desses produtos. Isto porque ou as diferentes formas comportam-se agronomicamente de maneira semelhante ou comportam-se de maneiras distintas mas tecnicamente reconhecidas e adequadamente avaliadas.

Essa situação, contudo, não se mostra a mesma em relação ao nutriente fósforo. Esse nutriente ocorre numa variedade grande de formas possíveis de serem usadas como fertilizantes e diferentes nas suas características físicas, químicas e principalmente agronômicas. Por outro lado não se conseguiu ainda reconhecer, ou ao menos adotar, satisfatoriamente uma distinção agronômica entre as diferentes formas de fósforo (KILLMER \& WEBB, 1969; CHIEN, 1975; PHILLIPS, 1975). Como consequência, nestas condições a adoção de qualquer técnica de laboratório para interpretar o binômio "quantidade - eficiência agronômica" do fósforo contido nos fertilizantes fica comprometida, principalmente as baseadas no emprêgo de extratores químicos.

Os critérios de laboratório empregados para a avaliação do fósforo em fertilizantes são todos baseados em extração química, sendo usados como extratores a água, a solução neutra de citrato de amônio, a solução de ácido cítrico a $2 \%$ e a solução de ácido fórmico a 2\%. Em todos esses extratores tem sido reconhecidas vantagens e, ao mesmo tempo desvantagens (JACOB \& HILL, 1953; CATANI, NASCIMENTO \& COSTA, 1956; CATANI, 1970) .

A solução de ácido cítrico a 2\% foi sugerida por Wagner em 1899 para avaliar o fósforo de escórias básicas, na proporção de 1:100, isto é, $5,0 \mathrm{~g}$ da amostra para $500 \mathrm{ml}$ daquela solução; esse critério foi adotado oficialmente nos Estados Unidos para avaliar o fósforo daqueles materiais até 1949 , sendo posteriormente substituído pela solução de citrato de amônio (JACOB \& HILL, 1953) .

No Brasil a solução de ácido cítrico a $2 \%$ tem sido empregada sob diferentes condições e com vários objetivos: até 1961 foi usada segundo a técnica de Wagner, para avaliar o fósforo contido em escórias e nas rochas fosfatadas; com o Decreto 50.146 de 27/01/61 passou a ser usada na avaliação do fósforo naqueles materiais, mas na proporção de 1:300 e sem a caracterização das condições de agitação; permitiu também seu emprego em misturas de fertilizantes contendo fosfato de rocha, desde que a massa da amostra analisada contivesse $1,0 \mathrm{~g}$ de rocha fosfatada. $\mathrm{E}$ recentemente, com o Decreto 75.583 de 09/04/75 a legislação foi re- 
formulada e a solução de ácido cítrico a $2 \%$, com extração efetuada de acordo com a técnica de Wagner, veio a constituir o principal critério para avaliar o binômio "quantidade - eficiência agronômica" do fósforo contido em qualquer natureza de fertilizante.

Esse critério atualmente adotado pela legislação brasileira é original. E não está correlacionado com resultados de experimentos sobre a eficiência agronômica relativa das diferentes formas de fertilizantes fosfatados, correlação essa, aliás, que tem sido extremamente problemática e polêmica em relação a todos os extratores químicos usados na avaliação, em condições de laboratório, do fósforo contido nos fertilizantes. Sua adoção oficial fundamentou-se em duas características vantajosas que esse extrator apresenta em relação a solução de citrato de amônio, isto é, sua menor ação extratora sobre o fósforo dos fosfatos de ferro e de alumínio e a relativa simplicidade da técnica de extração.

Embora a solução de ácido cítrico a $2 \%$ já tenha sido amplamente empregada na avaliação do fósforo contido em fertilizantes fosfatados insolúveis em água, ao que parece não foi ainda experimentada na avaliação do fósforo em fertilizantes que apresentam componentes solúveis em água, a não ser a opção da legislação brasileira que vigorou de 1961 a 1975 conforme já foi referido, a qual efetivamente também não deve ter sido usada. E nestas condições certos aspectos analíticos do comportamento dessa solução ainda são desconhecidos.

Neste trabalho estudou-se o comportamento da solução de ácido cítrico a $2 \%$ quando aplicada na avaliação do fósforo em fertilizantes simples e misturas, ambos contendo componentes solúveis em água, e efetuando-se a extração sob duas condições: diretamente na amostra e, portanto, em presença dos componentes solúveis em água, conforme o critério da legislação brasileira atual e após a extração dos componentes solúveis em água, à semelhança da técnica da extração classicamente estabelecida para a solução de citrato de amônio. Os resultados foram comparados entre si e com os obtidos pelo critério da solubilidade em solução de citrato de amônio (OFFICIAL METHODS OF ANALYSIS OF THE A.O.A.C., 1975).

\section{MATERIAL E MÉTODOS}

\section{MATERIAL}

O material constou de produtos comerciais dos fertilizantes superfosfato simples, superfosfato triplo, fosfato monoamônico (MAP), fosfato diamônico (DAP) nitrofosca e de misturas preparadas em laboratório e contendo fertilizantes fosfatados insolúveis em água; destes foram escolhidos a farinha de ossos degelatinados, o hiperfosfato e a apatida de Araxá, por apresentarem alta, média e baixa 
solubilidade na solução de ácido cítrico a $2 \%$ na relação $1: 100$, respectivamente. A composição dessas misturas está descrita no QUADRO 1.

QUADRO 1 - Composição porcentual das misturas de fertilizantes preparados em laboratório

\begin{tabular}{|c|c|c|c|}
\hline \multirow{2}{*}{ Componentes } & \multicolumn{3}{|c|}{ MISTURAS } \\
\hline & A & B & $\mathrm{C}$ \\
\hline Fosfato diamônico & 30 & & \\
\hline Sulfato de amônio & & 50 & \\
\hline Uréia & 25 & & 25 \\
\hline Superfosfato triplo & & 20 & 35 \\
\hline Farinha de ossos degel. & 20 & & \\
\hline Hiperfosfato * & & 20 & \\
\hline Apatita de Araxá * & & & \\
\hline Cloreto de potássio & 30 & 10 & 20 \\
\hline
\end{tabular}

* Essas rochas fosfatadas foram usadas com grau de finura tal que $100 \%$ passaram em peneira 200 .

O preparo das amostras constou de homogeneização, moagem até serem totalmente passadas em peneira $n .^{\circ} 40$, nova homogeização e conservação em recepiente hermético.

\section{MÉTODOS}

Determinação do fósforo total, solúvel em água e insolúvel em solução de citrato de amônio. Conforme descrito no OFFICIAL METHODS OF ANALYSIS OF THE A.O.A.C. (1975) e por CATANI (1973).

Determinação do fósforo solúvel em solução de ácido cítrico a $2 \%$, diretamente na amostra. Conforme o método descrito por CATANI (1973) diferindo apenas na relação entre a massa de amostra e o volume da solução de ácido cítrico a $2 \%$; a relação usada foi de $1: 100$, isto é, $1.000 \mathrm{~g}$ da amostra integral onde o fósforo foi extraído com $100 \mathrm{ml}$ da referida solução, em erlenmeyer de $250 \mathrm{ml}$ e agitação mecânica. A amplitude de concentração de fósforo usada na curva padrão foi de 2,0 a 4,0 mg de $\mathrm{P}_{2} \mathrm{O}_{5}$ por $100 \mathrm{ml}$.

Determinação do fósforo solúvel em solução de ácido cítrico a $2 \%$, após a extração dos componentes solúveis em água. Essa determinação foi feita como a anterior, usando-se como amostra o resíduo que restou 
no papel de filtro após a extração dos componentes solúveis no preparo do extrato para a determinação do fósforo solúvel em água. A extração do fósforo solúvel em solução de ácido cítrico foi feita em presença do papel de filtro.

\section{RESULTADOS OBTIDOS E DISCUSSÃO}

Todas as amostras foram analisadas em relação ao seu conteúdo de fósforo total, fósforo solúvel em água, fósforo solúvel em solução de ácido cítrico a 2\% (relação 1:100) quando extraído diretamente e quando extraído após a eliminação dos componentes solúveis em água e fósforo insolúvel em solução de citrato de amônio. Os resultados estão descritos no QUADRO 2.

QUADRO 2 - Resultados das determinações do fósforo contido nos fertilizantes simples e nas misturas (média de 3 determinações).

\begin{tabular}{|c|c|c|c|c|c|}
\hline \multirow[b]{2}{*}{ Fertilizantes } & \multicolumn{5}{|c|}{$\%$ de $\mathrm{P}_{2} \mathrm{O}_{5}$} \\
\hline & totàl & $\begin{array}{l}\text { Sol. em } \\
\text { água }\end{array}$ & $\begin{array}{l}\text { Sol ác. cí- } \\
\text { trico dire- } \\
\text { tamente } \\
\quad(1: 100)\end{array}$ & $\begin{array}{l}\text { Sol. ác. cit. } \\
\text { após ex- } \\
\text { tração } \\
\text { comp. sol. } \\
\text { em água } \\
(1: 100)\end{array}$ & $\begin{array}{l}\text { isol. em } \\
\text { citrato de } \\
\text { anônio } \\
(1: 100)\end{array}$ \\
\hline & 20,80 & 14,78 & 16,77 & 4,06 & 1,72 \\
\hline Superfosfato triplo & 46,24 & 36,74 & 40,86 & 7,42 & 1,45 \\
\hline $\begin{array}{l}\text { Fosfato monoámônico } \\
\qquad(\text { MAP) }\end{array}$ & 53,52 & 49,66 & 50,62 & 2,71 & 0,31 \\
\hline $\begin{array}{l}\text { Fosfato diamônico } \\
\qquad(\text { DAP })\end{array}$ & 47,77 & 40,62 & 42,99 & 2,76 & 0,57 \\
\hline Nitrofosca & 13,53 & 5,99 & 13,03 & 7,51 & 1,06 \\
\hline Mistura A & 20,46 & 13,59 & 20,40 & 6,80 & 0,00 \\
\hline Mistura $B$ & 16,05 & 7,53 & 12,75 & 7,09 & 2,13 \\
\hline Mistura C & 21,89 & 12,49 & 17,18 & 5,64 & 5,78 \\
\hline
\end{tabular}

Comparação entre os teores de fósforo solúvel na solução de ácido citrico a 2\% (1:100) obtidos sob duas técnicas de extração: diretamente e após a extração dos componentes solúveis em água.

$\mathrm{Na}$ extração do fósforo em fertilizantes pela solução de ácido cítrico a $2 \%$, quando efetuada diretamente na amostra integral, considera-se 
que seja extraído todo o fósforo solúvel em água e a fração solúvel em solução de ácido cítrico da parte insolúvel em água. Contudo, como nem todo o fósforo insolúvel em água é solúvel na solução de ácido cítrico, o equilíbrio dessa dissolução pode ser afetado pela presença de componentes solúveis. Esse efeito pode ser observado comparando o teor de fósforo solúvel na solução de ácido cítrico quando determinado diretamente e a soma dos teores de fósforo solúvel em água e solúvel na solução de ácido cítrico após a extração dos componentes solúveis em água. Esses teores de fósforo determinados nos fertilizantes acham-se descritos no QUADRO 3.

QUADRO 3 - Comparação entre o teor de fósforo solúvel na solução de ácido cítrico a $2 \%$ obtido por extração direta e o teor de fósforo correspondente a soma dos teores solúvel em água e solúvel na solução de ácido cítrico a $2 \%$ após a extração dos componentes solúveis $(1: 100)$.

\begin{tabular}{|c|c|c|c|}
\hline \multirow[b]{2}{*}{ Fertilizantes } & \multicolumn{3}{|c|}{$\%$ de $\mathrm{P}_{2} \mathrm{O}_{5}$} \\
\hline & $\begin{array}{c}\text { sol. ác. cítrico } \\
\text { diretamente } \\
(1: 100)(1)\end{array}$ & $\begin{array}{l}\text { sol. em água }+ \\
\text { sol. ac. cítrico } \\
\text { após extração } \\
\text { comp. sol. em } \\
\text { água }(1: 100)(2)\end{array}$ & Diferença 2-1 \\
\hline Superfosfato simples & 16,77 & 18,84 & 2,07 \\
\hline Superfosfato triplo & 40,86 & 44,16 & 3,30 \\
\hline Fosfato monoainônico (MAP) & 50,62 & 52,37 & 1,75 \\
\hline Fosfato diamônico (DAP) & 42,99 & 43,38 & 0,39 \\
\hline Nitrofosca & 13,03 & 13,50 & 0,47 \\
\hline Mistura A (com far. de ossos) & 20,40 & 20,39 & $-0,01$ \\
\hline Mistura B (com hiperfosfato) & 12,75 & 14,62 & 1,87 \\
\hline Mistura C (com fosfato Araxá) & 17,18 & 18,30 & 0,95 \\
\hline
\end{tabular}

Em todos os fertilizantes estudados o teor de fósforo obtido pela soma dos teores solúvel em água e solúvel na solução de ácido cítrico a 2\% após a extração dos componentes solúveis em água foi maior que o teor solúvel (de fósforo) na solução de ácido cítrico efetuando-se a extração diretamente na amostra integral, exceto para a mistura A. Isso permite concluir que a extração do fósforo, pela solução de ácido cítrico a $2 \%$, dos componentes insolúveis em água é afetada pela presença dos componentes solúveis em água, pelo menos na relação estudada (1:100) ou superiores. A equivalência dos resultados obtidos nas duas técnicas de extração para a mistura A deve-se atribuir ao fato do componente insolúvel em água presente nessa mistura ser a farinha de ossos degelatinados cujo fósforo é altamente solúvel nesse extrator. 
Comparação entre a solubilidade da fração insolúvel em água dos fertilizantes fosfatados, na solução de ácido cítrico a $2 \%$ e na solução. de citrato de amônio.

A determinação do fósforo solúvel na solução do ácido cítrico a $2 \%$ efetuada no resíduo que resta no papel de filtro após a extração dos componentes solúveis em água é semelhante a determinação do fósforo solúvel na solução de citrato de amônio de acordo com o método classicamente recomendado (OFFICIAL METHODS OF ANALYSIS OF THE A.O.A.C., 1975). Isso permite uma comparação mais estreita entre esses dois extratores. Os resultados dessas duas determinações estão relatados no QUADRO 4, onde os dados relativo a porcentagem de $\mathrm{P}_{2} \mathrm{O}_{5}$ solúvel em solução de ácido cítrico a $2 \%$ após a extração dos com-

QU.ADRO 4 - Teores de fósforo extraído da fração insolúvel em água dos fertilizantes, pelas soluções de ácido cítrico a $2 \%$ e de citrato de amônio.

\begin{tabular}{lccc}
\hline & $\% \mathrm{P}_{2} \mathrm{O}_{5}$ & \\
\cline { 2 - 4 } Fertilizantes & sol. ác. cítrico & sol. em sol. & Diferença 2-1 \\
& após extração & citrato de amônio & \\
comp. sol. em & $(1: 100)(2)$ & \\
água $(1: 100)(1)$ & & & \\
& & &
\end{tabular}

Superfosfato simples

Superfosfato triplo

Fosfato monoamônico (MAP)

Fosfatọ diamônico (DAP)

Nitrofosca

Mistura A

Mistura 13

Mistura $\mathrm{C}$

$\begin{array}{rrr}4,06 & 4,30 & 0,24 \\ 7,42 & 8,05 & 0,63 \\ 2,71 & 3,55 & 0,84 \\ 2,76 & 4,58 & 1,82 \\ 7,51 & 6,48 & -1,03 \\ 6,80 & 6,87 & 0.07 \\ 7,09 & 6,39 & -0,70 \\ 5,64 & 3,62 & -2,02\end{array}$

ponentes solúveis são os mesmos apresentados no QUADRO 2 e os dados relativos a porcentagem de $\mathrm{P}_{2} \mathrm{O}_{5}$ solúvel na solução de citrato de amônio foram calculados pela expressão: $\% \mathrm{P}_{2} \mathrm{O}_{\overline{5}}$ sol. citrato de amônio: $\% \mathrm{P}_{2} \mathrm{O}_{5}$ total - $\left(\% \mathrm{P}_{2} \mathrm{O}_{5}\right.$ sol. em água $+\% \mathrm{P}_{2} \mathrm{O}_{5}$ insol. em solução de citrato de amônio) .

Observa-se que, efetuando a extração com solução de ácido cítrico a $2 \%$ adotando a mesma técnica de extração classicamente usada com a solução de citrato de amônio, isto é, realizando a extração após a separação dos componentes solúveis em água os fertilizantes simples solúveis em água apresentaram solubilidade em solução de citrato de amônio superior à solubilidade de ácido cítrico a $2 \%$. Porém, as misturas de 
fertilizantes contendo rochas fosfatadas apresentaram solubilidade em solução de citrato de amônio inferior à solubilidade em solução de ácido cítrico a 2\%. Apenas a mistura A que continha farinha de ossos degelatinados apresentou solubilidade semelhante nesses dois extratores.

Sabe-se que essas duas soluções extratoras tem eficiência equivalente na solubilização do fosfato bicálcio e do fosfato tricálcio das farinhas de ossos, em iguais condições de extração. A maior solubilidade em solução de citrato de amônio apresentada pelos fertilizantes fosfatados simples solúveis em água é consequência da presença de fosfatos de ferro e de alumínio nesses materiais; como se sabe os referidos fosfatos são mais solúveis em solução de citrato de amônio do que em solução de ácido cítrico em semelhantes condições de solubilização (JACOB \& HILL, 1953; CATANI, NACIMENTO \& COSTA, 1956) . Por outro lado, o maior teor de fósforo obtido com a solução de ácido cítrico a $2 \%$ nas misturas de fertilizantes contendo rochas fosfatadas (misturas B e C) baseia-se no fato desses fosfatos serem mais solúveis nesse extrator do que em solução de citrato de amônio (CATANI, NASCIMENTO \% COSTA, 1956; ANDA, 1975.

Comparação entre as formas de avaliação do fósforo contido nos fertilizantes com base nos extratores água, solução de ácido cítrico a $2 \%$ e soluçãode citrato de amônio.

Com os dados do QUADRO 2, foram obtidos os do QUADRO 5 onde são descritos os teores de $\mathrm{P}_{2} \mathrm{O}_{5}$ avaliados nos fertilizantes segundo diversos critérios, isto é, o critério da solubilidade em solução de ácido cítrico

QUADRO 5 - Teores de fósforo nos diferentes fertilizantes segundo vários critérios de avaliação.

\begin{tabular}{|c|c|c|c|}
\hline \multirow[b]{2}{*}{ Fertilizantes } & \multicolumn{3}{|c|}{$\% \quad \mathrm{P}_{2} \mathrm{O}_{5}$} \\
\hline & $\begin{array}{l}\text { sol. ác. cítrico } \\
\text { diretamente }\end{array}$ & $\begin{array}{l}\text { sol. água + sol. } \\
\text { ác. cítrico após } \\
\text { extração comp. } \\
\text { solúveis. }(1: 100)\end{array}$ & $\begin{array}{l}\text { sol. água }+ \text { ci- } \\
\text { citrato de } \\
\text { amônio }(1: 100)\end{array}$ \\
\hline
\end{tabular}

\begin{tabular}{lccc}
\hline \hline Superfosfato simples & 16,77 & 18,84 & 19,08 \\
Superfosfato triplo & 40,86 & 44,16 & 44,79 \\
Fosfato monoamônico (MAP) & 50,62 & 52,37 & 53,21 \\
Fosfato diamônico (DAP) & 42,99 & 43,38 & 45,20 \\
Nitrofosca & 13,03 & 13,50 & 12,47 \\
Mistura A & 20,40 & 20,39 & 20,46 \\
Mistura B & 12,75 & 14,62 & 13,92 \\
Mistura C & 17,80 & 18,30 & 16,11 \\
\hline
\end{tabular}


a $2 \%$ obtida diretamente (critério brasileiro), o critério da solubilidade em água mais a solubilidade em citrato de amônio ("fósforo disponível" - critério adotado pelos Estados Unidos) e um critério semelhante ao do fósforo disponível, mas empregando solução de ácido cítrico a $2 \%$.

Esses dados mostram que para os fertilizantes simples, o critério baseado na extração com a solução de ácido cítrico a $2 \%$ efetuada diretamente na amostra proporcionou resultados inferiores em relação aos outros dois critérios estudados; e o critério baseado na soma dos teores de fósforo solúvel em água e solúvel na solução de ácido cítrico a $2 \%$ após a extração dos componentes solúveis em água apresentou resultados mais próximos dos proporcionados pelo critério do "fósforo disponível". Por outro lado, para as misturas as diferenças entre os resultados apresentados pelos três critérios não foram sistemáticos, demonstrando que o comportamento de cada critério em relação às misturas de fertililizantes depende da natureza do material fosfatado que as constitui.

A fim de tornar mais clara e objetiva a comparação entre essas técnicas de extração estudadas, calculou-se a solubilidade da fração do fósforo insolúvel em água contida nos fertilizantees, em cada técnica de

QUADRO 6 - Porcentagem de fósforo $\left(\mathrm{P}_{2} \mathrm{O}_{5}\right)$ solubilizado da fração insolúvel em água contida nos fertilizantes, pelas diferentes técnicas de extração.

\begin{tabular}{|c|c|c|c|c|}
\hline \multirow[b]{2}{*}{ Fertilizantes } & \multirow[b]{2}{*}{$\begin{array}{l}\% \mathrm{P}_{2} \mathrm{O}_{5} \\
\text { insol. em } \\
\text { água }\end{array}$} & \multicolumn{2}{|c|}{$\% \mathrm{P}_{2} \mathrm{O}_{5}$ solubilizado na } & \multirow[b]{2}{*}{$\begin{array}{l}\text { sol. citrato } \\
\text { de amônio } \\
\quad(1: 100)\end{array}$} \\
\hline & & $\begin{array}{l}\text { sol. ác. cítrico } \\
\text { diretamente } \\
(1: 100)\end{array}$ & $\begin{array}{l}\text { sol. ác. cítrico } \\
\text { após extr. } \\
\text { comp. solú- } \\
\text { veis em água } \\
\quad(1: 100)\end{array}$ & \\
\hline Superfosfato simples & 6,02 & 33,06 & 67,44 & 71,43 \\
\hline Superfosfato triplo & 9,50 & 43,37 & 78,11 & 84,74 \\
\hline $\begin{array}{l}\text { Fosfato monoamônico } \\
\text { (MAP) }\end{array}$ & 3,86 & 24,87 & 70,21 & 91,97 \\
\hline $\begin{array}{l}\text { Fosfato diamônico } \\
\text { (DAP) }\end{array}$ & 5,15 & 46,02 & 53,59 & 88,93 \\
\hline Nitrofosca & 7,54 & 93,37 & 99,60 & 85,94 \\
\hline $\begin{array}{l}\text { Mistura A (com farinha } \\
\text { de ossos) }\end{array}$ & 6,87 & 99,13 & 99,98 & 100,00 \\
\hline $\begin{array}{l}\text { Mistura B (com hiper- } \\
\text { fosfato) }\end{array}$ & 8,52 & 61,27 & 83,21 & 75,00 \\
\hline $\begin{array}{l}\text { Mistura C (com fosf. } \\
\text { Araxá }\end{array}$ & 9,43 & 49,43 & 59,80 & 38,39 \\
\hline
\end{tabular}


extração e em função do teor de fósforo insolúvel em água presente. No critério baseado no uso da solução de ácido cítrico a $2 \%$ com extração direta na amostra, a solubilidade da fração insolúvel foi calculada subtraindo o teor de $\mathrm{P}_{2} \mathrm{O}_{5}$ solúvel em água do teor de $\mathrm{P}_{2} \mathrm{O}_{5}$ determinado pelo citado critério. Os dados estão no QUADRO 6.

Conforme se observa, nos fertilizantes simples o fósforo contido na fração insolúvel em água apresentou uma solubilidade crescente nas soluções de ácido cítrico a $2 \%$ com extração direta, de ácido cítrico a $2 \%$ com extração efetuada após a eliminação dos componentes solúveis em água e na de citrato de amônio. Nas misturas de fertilizantes, a fração insolúvel em águe apresentou maior solubilidade na solução de ácido cítrico a $2 \%$ com extração efetuada após a eliminação dos componentes solúveis em água; e a menor solubilidade foi apresentada pela fração insolúvel do nitrofosca e da mistura C (que tinha apatita de Araxá) na solução de citrato de amônio e pela fração insolúvel da mistura B (que tinha hiperfosfato) na solução de ácido cítrico a $2 \%$ com extração direta. A fração insolúvel da mistura A (que continha farinha de ossos) apresentou solubilidade semelhante nos três critérios.

\section{CONCLUSÕES}

Os resultados obtidos permitiram as seguintes conclusões:

a) a extração do fósforo contido na fração insolúvel em água dos fertilizantes fosfatados simples e misturas pela solução de ácido cítrico a $2 \%$, na relação $1: 100$, foi afetada pela presença dos componentes solúveis em água.

b) a fração do fósforo insolúvel em água dos fertilizantes simples solúveis em água apresentou maior solubilidade na solução de citrato de amônio e menor na solução de ácido cítrico a 2\% com extração efetuada na amostra integral.

c) a fração do fósforo insolúvel em água de misturas de fertilizantes contendo rochas fosfatadas apresentou a maior solubilidade na solução de ácido cítrico a $2 \%$, após a eliminação dos componentes solúveis em água; as menores solubilidades foram apresentadas na solução de ácido a $2 \%$ com extração direta pela mistura que continha hiperfosfato, e na solução de citrato de amônio pela mistura que continha apatita de Araxá. A mistura que continha farinha de ossos degelatinados apresentou solubilidade semelhante nas três técnicas de extração estudadas. 
SLMMARY

\section{EVALUATION OF PHOSPHORUS IN FERTILIZERS WITH $2 \%$ CITRIC ACID SOLUTION: EXTRACTION TECHNIQUES}

In this paper was studied the behavior of the $2 \%$ citric acid solution for phosphorus evaluation in simple fertilizers and mixtures in two extraction conditions: directly in the sample and, therefore,, in presence of water soluble components, and after the extration of water soluble components, that is to say the same classic extraction technique adopted for ammonium citrate solution.

The results were compared among themselves and with those attained by water and ammonium citrate criteria making possible to conclude that the direct citric (ratio 1:100) is affect by the presence of water soluble components; also, the water insoluble fraction of the simple fertilizers presents greater solubility in ammonium citrate solution the water insoluble fraction of the fertilizer mixtures containig rock phosphates presented greater solubility int the citric solution with extraction after the elimination water soluble components and the smaller solubilities were presented in the citric solution with direct extration by the mixture containning hyperphosphate but in the ammonium citrate solution by he mixture containning Araxá apatite. The mixture containning degelatined bones meal presented the same solubility in three extraction techinique studied.

\section{LITERATURA CITADA}

CATANI, R.A.; A.C. NASCIMENTO \& N.A. COSTA, 1956. Fertilizantes fosfatados, classificação e interpretação dos resultados analíticos. Anais da 4.a reunião Brasileira de Ciências do Solo (Belo Horizonte) p. 49-64, Publicado pela Sociedarde Brasileira de Ciência do Solo, Rio de Janeiro - Brasil.

CATANI, R.A., 1970. A solubilidade de fosfatos naturais em solução de ácido cítrico a 2\%, na proporção 1:200. Anais da Esc. Sup. Agric. "Luiz de Queiroz", 27:1-14.

CHIEN, S.H., 1975. Problems and Theory of Evaluating the Chemical Reactivity Scale of Phosphate Rock for Direct Application. 21 pp. (Intern. Fert. Devlop. Center, USA).

JACOB, K.D. \& W.L. HILL, 1953. Laboratory Evaluation of Phosfate Fertilizers. Em: Soil and Fertilizer Phosphorus in Crop Nutrition. Vol. VI da série Agronony, Cap X, p. 299-345. Ed. by W.H. PIERRE \& A.C. NORMAN, Academic Press Inc., Publishers.

KILMER, V.J. \& WEBB, 1968. Agronomic Effectiveness of Different Fertilizers. Em: Changing Patterns in Fertilizer Use, p. 33-65. Soil Science Society of America, Inc. Madison, Wisconsin, USA.

OFFICIAL METHODS OF ANALYSIS OF THE A.O.A.C., 1975. 12 th ed., Published by the Ass. Off. Anal. Chem., Washington, D.C.

PHILIPS, A.B., 1975. Comunicação particular. 
